\title{
Development of the Gait Outcomes Assessment List for Lower Limb Differences (GOAL-LD) Questionnaire: A Patient and Parent Reported Outcome Measure for Pediatric Lower-limb Deformity
}

Jennifer A Dermott ( $\nabla$ jennifer.dermott@sickkids.ca )

Hospital for Sick Children, 555 University Avenue, Room S229, Toronto https://orcid.org/0000-00019740-7197

\author{
Virginia Wright \\ Holland Bloorview Kids Rehabilitation Hospital \\ Nancy M Salbach \\ University of Toronto \\ Unni G Narayanan \\ Hospital for Sick Children
}

\section{Research}

Keywords: Gait Outcomes Assessment List (GOAL), health related quality of life (HRQL), lower-limb differences (LD)

Posted Date: August 28th, 2020

DOI: https://doi.org/10.21203/rs.3.rs-61641/v1

License: (c) (1) This work is licensed under a Creative Commons Attribution 4.0 International License. Read Full License 


\section{Abstract}

Purpose: To develop a priority-based patient /parent reported outcome measure for children with lowerlimb differences (LD) by adapting the Gait Outcomes Assessment List (GOAL) questionnaire.

Methods: Guided by a conceptual framework of patient priorities, the GOAL questionnaire was iteratively modified and its sensibility evaluated by field-testing it on children with LD and their parents. Cognitive interviews were conducted with a subgroup of these children, and an e-survey administered to a multidisciplinary group of health care professionals with expertise in paediatric LD. Findings were integrated to create the final version of the GOAL-LD.

Results: Twenty-five children, 20 parents, and 31 healthcare professionals evaluated the content and sensibility of the GOAL, with an emphasis on the relevance and importance of the items to patients' health related quality of life (HRQL). This resulted in the retention of 26 of the original 50 items, elimination of 12 , modification of 12 , and addition of seven new items. The new $45-$ item GOAL-LD questionnaire was shown to be sensible and its content deemed important.

Conclusion: The GOAL-LD questionnaire has a high level of face and content validity, and sensibility. It comprehensively captures the HRQL goals and outcomes that matter to children with LD and their parents. Following further psychometric evaluation, the GOAL-LD may serve as a much needed patient and parent reported outcome measure for this population.

\section{Introduction}

Pediatric lower limb differences (LD) include a wide spectrum of congenital, developmental and acquired causes of limb deficiencies, deformities, and length discrepancies. Congenital lower-limb deficiencies, including the absence or shortening of a limb or part of a limb, have a reported incidence of 2-7 in 10 000 births [1]. About 1 in 1000 people have a clinically relevant length discrepancy greater than 2 centimetres [2]. Lower limb deformities and length discrepancies are associated with a number of developmental conditions (e.g., Blount's disease), or may be acquired as a consequence of partial or complete injuries to the growth plate secondary to fractures, infection or neoplasms. These conditions are associated with abnormal gait and increased biomechanical effort [3-5], altered appearance of the limb, and psychosocial consequences $[3,6]$. Children with LD are faced with a variety of treatment options and often undergo multiple interventions throughout their childhood; yet we know very little about how this may impact their health related quality of life (HRQL) [7]. The benefits of these interventions, let alone 
their comparative effectiveness, are poorly quantified because there are no validated outcome measures developed for this population.

The International Classification of Functioning, Disability and Health (ICF) [8] is a useful framework to conceptualize the consequences and outcomes of LD, illustrated in Fig. 1. The management and evaluation of care should be informed by "multidimensional assessment leading to targeted interventions based on patient (parent) perceived needs" [9]. The ultimate goal of treating children with LD is to improve HRQL, optimizing function and maximizing participation, by addressing the physical, social and psychological effects of their LD. Research on pediatric LD has focused on the ICF domain of Body Functions and Structures [8] such as radiographic measures of limb alignment and length, post-operative complications, and time to heal [10]. Although these are important markers of the technical success of an intervention that address the physical impairments, one cannot assume that these correspond with HRQL outcomes that matter most to children/parents and are aligned with their priorities and goals. These are better captured in the ICF domains of Activity and Participation, using patient-reported outcome measures (PROMs) that are designed to measure these outcomes [11]. To date, generic measures of health status or HRQL (e.g., Child Health Questionnaire, [12]; PODCI [13]) have shown limited discriminative ability and responsiveness for this population, $[7,6,14-16]$ highlighting the imperative for a more meaningful PROM for children with LD.

The Priority Framework for Outcome Assessment $[17,18]$, depicted in Fig. 2, illustrates that to be meaningful to an individual, an outcome measure must incorporate their priorities and goals. To affect $H R Q L$, interventions must address a patient's goals, and effectiveness must be judged based on whether these goals were met. The Gait Outcomes Assessment List (GOAL) $[19,20]$ questionnaire is a multidimensional, self-administered child- and parent-report that was developed using the Priority Framework as its conceptual framework. The GOAL was created to evaluate outcomes based on the broad range of children's and parents' goals for gait related interventions for children with cerebral palsy, with a view to ultimately applying it to other childhood conditions associated with lower extremity impairments. The GOAL is a hybrid measure, combining the specificity of an individualized measure that identifies patient specific priorities or goals for treatment, with the standardization of a fixed item PROM. While individualized measures such as the Canadian Occupational Performance Measure (COPM) [21] and Goal Attainment Scaling (GAS) [22, 23] are well documented in pediatric rehabilitation outcomes research, most studies also employ a fixed item functional measure as a parallel tool [24] to evaluate intervention effectiveness at a group level and/or to provide predictive or discriminative information [25]. A questionnaire that combines the benefits of individualization and standardization is uniquely comprehensive and reduces the need to administer multiple questionnaires to patients.

The original version of the parent- and child-reported GOAL questionnaire [26] used as the starting point in this study, consists of 50 items across seven domains: (A) Activities of Daily Living (ADL) \& Independence, (B) Gait Function \& Mobility, (C) Pain/Discomfort/Fatigue, (D) Physical Activities, Sport \& Recreation, (E) Gait Appearance, (F) Use of Braces \& Assistive Devices, and (G) Body Image \& SelfEsteem. Domains associated with tasks or activities use a 7-point ordinal scale anchored from 0: 
"extremely difficult/impossible" to 6: "no problem at all" with a 4-point modifier on how much assistance (from 0: "total" to 3: "independent") is required to accomplish each task or activity. Symptoms such as pain or fatigue are rated on a 6-point scale of frequency, from 0: "every day" to 5: "none of the time" as well as their intensity (0: "severe" to 2: "mild"). Domains that examine the respondent's feelings use a 5point ordinal scale from 0: "very unhappy" to 4: "very happy. Item scores are standardized (raw item score divided by total possible score for that item, multiplied by 100). Domain scores are the average of the standardized item score for each item in that domain, and the total score is the average of all the standardized item scores, reported from 0 to 100.

A key feature of the GOAL questionnaire is that for each item, the respondent also rates how important a goal it is to improve on that item using a 5-point scale from not a goal to extremely important. These importance ratings do not contribute to the total or domain score, but highlight, for each individual, which items are most important for improvement. Respondents may also specify additional goals and rate the importance of improving these.

Although the GOAL was developed and has been validated for children with ambulatory cerebral palsy [20], its focus on patient priorities and coverage of all domains of the ICF associated with gait-related problems [19] provides the foundation for developing a parallel measure for pediatric LD. Given that CP with its neurologic impairments is sufficiently different from LD, some of the content of the GOAL might not be as relevant to children with LD, and some important content to LD might be missing.

The aims of this study were to (i) evaluate the suitability of the items of the GOAL and its sensibility (face and content validity, comprehensibility, clarity of instruction, appropriateness of response scale, and ease of usage) from the perspective of children with LDs, their parents, and health care professionals (HCPs) with expertise in this population, and to (ii) adapt the GOAL based on the input of these stakeholders to create the GOAL-LD. Permission to proceed with development of the GOAL-LD was granted by the GOAL's developer (UG Narayanan, oral communication, September 2011).

\section{Methods}

This two-phased study used an iterative process that considered all key stakeholders' perspectives. Phase 1 involved patients and their parents, and Phase 2 involved health care professionals (HCPs) as is illustrated in Fig. 3.

\section{Participants}

Children with LDs (ages 9 to 18 years) and/or their parents were recruited from the Limb Reconstruction Program at the Hospital for Sick Children and the Prosthetic Clinic of Holland Bloorview Kids Rehabilitation Hospital, both university-affiliated centres. Children were excluded if they had upper-limb involvement, neuromuscular conditions, or acute or systemic illness such sarcoma, or juvenile arthritis. The international multi-disciplinary group of content expert HCPs was identified through membership lists of the International Limb Lengthening and Reconstruction Society (LLRS), and the British Limb 
Reconstruction Society (BLRS), whose members represent a large number pediatric lower-limb reconstruction centres around the world. In accordance with the Research Ethics Board-approved protocol, children and parents provided written, informed consent to participate, while survey completion by HCPs implied consent.

Phase 1: Children and Parent Perspectives

The GOAL questionnaire was administered by the first author to each of the participating children and/or their parents in a quiet room in the clinic setting. Participants scored each item and rated the importance of the goal to improve that item. The time to complete the questionnaire was documented. Children were invited to participate in a follow-up cognitive interview [27] [28]. These one-on-one interviews were guided by Feinstein's framework of sensibility [29], which defines sensibility as "an aggregate of properties that make up the commonsense aspect of an instrument" [27]. It is increasingly being applied to evaluating the quality of questionnaires [30].

The first author conducted these semi-structured interviews based on the Cognitive Pretesting Model for Children [28] to probe whether the questionnaire resonated with them. The study-specific interview guide is included in Additional file 1. Also tested were the child's understanding of words, phrases, and concepts that were deemed a priori by the development team to be potentially problematic (e.g., What do you think "symmetry" means?). Children were asked questions regarding the scale format and response options (e.g., Did you feel you were able to find your answer in the list of possible answers listed?), any items that should be added or eliminated, and their overall impressions of the questionnaire, including its length. This information was used to guide decisions about the acceptance, modification or elimination of items in subsequent versions of the questionnaire (initial version $=G O A L$, second version $=G O A L-L D_{d r a f t}$, and third version $=G O A L-L D_{\text {draft2 }}$ ), as described in the analysis. Recruitment was staged eight weeks apart so that each new version of the questionnaire was piloted with a different group of children and their parents.

Phase 2: Health Care Provider (HCP) Perspectives

HCPs received an introductory e-mail which included the GOAL-LD draft2 $_{\text {as }}$ an attachment and a link to an online feedback survey built for the study using FluidSurveys [31] The e-survey asked HCPs to rate each of the proposed GOAL-LD questionnaire items as: accept; accept with modification (and state the modification); or reject (and provide rationale for rejection). This was an adaptation of an item reduction approach used successfully by one of the authors in development of a previous outcome measure [32].

Additionally, HCPs were asked to list other items that should be included, and were invited to respond to four open-ended questions: (i) What do you consider to be the strengths of the GOAL-LD?; (ii) What do you consider to be the weaknesses of the GOAL-LD?; (iii) Would you consider use of the GOAL-LD in your clinical practice?; and (iv) Would you consider using the GOAL-LD for research purposes?

Data Analyses and Iterative Adaptation 
Analysis of the completed questionnaires in combination with the children's cognitive interview responses was conducted during Phase I after each stage of recruitment and informed the subsequent version of the questionnaire. Quantitative data analyses were performed using R for Mac OS X [33]. Children's detailed responses from the cognitive interviews were collated into a single document, allowing general themes to be identified.

\section{Phase 1}

Descriptive statistics (mean, median, standard deviation [SD], range) were calculated separately for children's and parents' item scores and importance ratings for each iteration of the questionnaire. Items were judged to perform poorly and considered for elimination if both child and parent item mean scores were within 0.5 of the maximum score (i.e., 5.5 to 6.0 on a 6-point scale) suggesting poor discriminative ability and unresponsiveness to change (ceiling effect), or if both the child and parent importance mean ratings were less than $0.5 / 4$, suggesting this item was seldom a goal for improvement. These extreme cut-off values were chosen to highlight the worst performing items, which were then examined alongside cognitive interview results to assess opportunities to modify, rather than prematurely eliminating items that may resonate with other children. Modified items and new item suggestions were considered in terms of redundancy and fit within the measurement concept and incorporated as appropriate into the next GOAL iteration to examine their performance.

The total number of child and parent participants and the number of GOAL-LD questionnaire iterations was based on achieving informational saturation, i.e., the point at which new suggestions related to content adaptation or to which novel input pertaining to sensibility were no longer forthcoming [34].

\section{Phase 2}

The HCP responses to the GOAL-LD draft2 were summarized for each item, and acceptance category percentages calculated. Items with at least $90 \%$ acceptance were retained in the GOAL-LD. Conversely, items with more than $10 \%$ reject responses were considered for elimination. The final decision about an item's fate also considered the child/parent responses to the GOAL-LD draft2 to obtain further feedback on its performance. New items suggested were adopted based on whether they fit conceptually and were not redundant. Responses to the open -ended questions related to the questionnaire's strengths/weaknesses and clinical/research utility were compiled into a single document, allowing general themes to be identified.

The child/parent responses to the GOAL-LD $D_{\text {draft2 }}$ and the results of the HCP e-survey were considered together in the development of the final version of the GOAL-LD.

\section{Results}

Forty-five participants, including 25 children (14 girls) with a mean age of 13.7 years (9.0 to 17.9 years) and 20 parents (16 mothers), were enrolled in Phase 1. Table 1 provides a summary of the participants' 
age (children) and gender (parents and children), categorized by the questionnaire version they were administered. Sixteen children had a congenital LD (e.g., fibular hemimelia), 5 acquired (e.g., posttraumatic growth arrest), and 4 developmental (e.g., genu varum). Total leg length discrepancies ranged from zero to $100 \mathrm{~mm}$, and deformity [35] ranged from none to greater than 15 degrees of malalignment. Additional file 2 further details children's diagnostic characteristics. Of the 25 children enrolled, one opted to review but not complete the GOAL questionnaire and agreed to participate in the cognitive interview. In total, 13 children participated in the cognitive interviews ( 8 for the GOAL and 5 for the GOAL-LD draft1). Thirty-one HCPs ( $81 \%$ orthopedic surgeons; $52 \%$ North American) completed the Phase 2 survey that reviewed the GOAL-LD draft2. A demographic summary of HCP respondents is provided in Table 2.

Table 1

Phase 1 participants by questionnaire version administered

\begin{tabular}{|c|c|c|c|c|c|}
\hline & Children & & & & Parents \\
\hline $\begin{array}{l}\text { Questionnaire } \\
\text { Administered }\end{array}$ & $\begin{array}{l}\text { GOAL } \\
\text { Completion } \\
\text { (n) }\end{array}$ & $\begin{array}{l}\text { Mean age } \\
\text { (SD) } \\
\text { Range }\end{array}$ & $\begin{array}{l}\text { Cognitive } \\
\text { Debrief }^{\mathrm{a}}(n)\end{array}$ & $\begin{array}{l}\text { Mean age } \\
\text { (SD) } \\
\text { Range }\end{array}$ & $\begin{array}{l}\text { GOAL } \\
\text { Completion } \\
(n)^{c}\end{array}$ \\
\hline GOAL & $\begin{array}{l}12 \\
\text { (7 girls/5 } \\
\text { boys) }\end{array}$ & $\begin{array}{l}14.8 \text { years } \\
(2.3) \\
12- \\
17 \text { years }\end{array}$ & $\begin{array}{l}8 \\
(5 \mathrm{girls} / 3 \\
\text { boys })\end{array}$ & $\begin{array}{l}15.7 \text { years } \\
(2.6) \\
13-17\end{array}$ & $\begin{array}{l}11 \\
\text { (9 mothers) }\end{array}$ \\
\hline GOAL-LD ${ }_{\mathrm{drft} 1}$ & $\begin{array}{l}5 \\
(3 \text { girls } / 2 \\
\text { boys) }\end{array}$ & $\begin{array}{l}11.8 \text { years } \\
(2.6) \\
9- \\
16 \text { years }\end{array}$ & $\begin{array}{l}5 \\
(2 \text { girls/3 } \\
\text { boys })\end{array}$ & $\begin{array}{l}13.2(2.7) \\
10-16\end{array}$ & $\begin{array}{l}3 \\
\text { (2 mothers) }\end{array}$ \\
\hline GOAL-LD ${ }_{\mathrm{drtt2}}$ & $\begin{array}{l}7 \\
\text { (4 girls/3 } \\
\text { boys) }\end{array}$ & $\begin{array}{l}13.4 \text { years } \\
(2.4) \\
9- \\
17 \text { years }\end{array}$ & $\mathrm{n} / \mathrm{a}$ & $\mathrm{n} / \mathrm{a}$ & $\begin{array}{l}6 \\
\text { (5 mothers) }\end{array}$ \\
\hline Total & $\begin{array}{l}24^{\text {b }} \\
(14 \text { girls/10 } \\
\text { boys) }\end{array}$ & $\begin{array}{l}13.7 \text { years } \\
(2.6) \\
9- \\
17 \text { years }\end{array}$ & $\begin{array}{l}13 \\
\text { (7 girls/6 } \\
\text { boys) }\end{array}$ & $\begin{array}{l}14.6(2.5) \\
10-17\end{array}$ & $\begin{array}{l}20 \\
\text { (16 mothers) }\end{array}$ \\
\hline $\begin{array}{l}{ }^{a} \text { cognitive deb } \\
\text { enrollment was } \\
\text { participate in a }\end{array}$ & $\begin{array}{l}\text { mple is a sub } \\
\text { Idren. One ch } \\
\text { ive debrief in }\end{array}$ & $\begin{array}{l}\text { ole of the ch } \\
\text { oted not to } \\
w_{1}{ }^{c} \text { each } p\end{array}$ & $\begin{array}{l}\text { Iren who cons } \\
\text { mplete the qu }\end{array}$ & $\begin{array}{l}\text { d to particip } \\
\text { onnaire (GOA } \\
\text { ild-parent } d \text { ) }\end{array}$ & $\begin{array}{l}\text { te, }{ }^{b} \text { total study } \\
\left.-L D_{\text {draft } 1}\right) \text { but di } \\
\text { d }\end{array}$ \\
\hline
\end{tabular}


Table 2

Demographics of phase 2 HCP respondents $(n=31)$

\begin{tabular}{|ll|}
\hline Demographics & $\mathbf{n}$ (out of 31) \\
\hline Healthcare Profession & 25 \\
\hline Pediatric Orthopedic surgeon & 4 \\
\hline Physical Therapist & 2 \\
\hline Other: Physical Therapy Practitioner, Nurse Practitioner & \\
\hline Experience working with children with LDs (years) & 6 \\
\hline$<5$ & 9 \\
\hline 5 to $<10$ & 5 \\
\hline $10-<15$ & 11 \\
\hline$>15$ & \\
\hline Country & 5 \\
\hline Canada & 11 \\
\hline United States & 10 \\
\hline United Kingdom & 3 \\
\hline Europe & 2 \\
\hline Unknown & \\
\hline Abbreviations: HCP, health care professional; LD, lower limb difference & \\
\hline
\end{tabular}

GOAL Content Adaptation

Item Addition

In total, seven new items were added, six derived from children's and parents' suggestions. These were retained in the final iteration based on the items' subsequent scoring performance and the HCPs' ratings. An item about wearing a prosthesis was introduced based on HCPs' recommendations and was included to increase the questionnaire's generalizability.

Item Modification

Three items were modified to increase their level of difficulty (e.g., carrying an object while walking (e.g., toy, doll, book, cellphone) became carrying heavy objects while walking (e.g., grocery bags, several schoolbooks). Other examples of modifications through the iterations include: i) three items that were split to improve their specificity ii) two items that were combined to minimize redundancy, and iii) and 3 
items that were moved to a different domain where the development team felt that they fit better conceptually. Six modifications were directly informed by HCP recommendations and involved wording to make items more explicit (e.g., walking on slippery or icy surfaces became walking on wet, slippery or icy surfaces) or to facilitate international utility (e.g., including metric and imperial measurements).

Item Elimination

In total, 12 original GOAL items were eliminated of which six were in the ADL category and removed due to poor item performance in field-testing. Walking for more than 15 minutes was eliminated because in the cognitive interviews, children could not distinguish this item from walking for more than 250 meters. The latter was retained because children were better able to conceptualize 250 meters ("from swimming", "from track and field") and it had lower item scores (i.e., considered more difficult). One item was eliminated based on HCP feedback related to perceived redundancy, and the development team agreed that moving quickly when in a hurry overlapped with running fast since both items were speed related. The latter was retained based on an overall lower item score and wider distribution (range) of scores within the GOAL-LD draft2.

An overview of the content adaptations is provided with full item-by-item details by iteration, in Additional file 3.

Sensibility Evaluation

\section{Comprehensibility}

No participant asked for assistance or language clarification during GOAL or GOAL-LD draft1 administration. During cognitive interviews, all children demonstrated that they could read and understand the meaning of words, phrases, and concepts in the questionnaire.

\section{Clarity of instruction}

Five participants indicated they had not read the instructions prior to completing the questionnaire. Further, it became clear that instructions with respect to item importance ratings were problematic. The intended purpose of these ratings was to capture how important a goal it was to improve on the item, allowing identification of items that contribute most to treatment related decision-making. During the cognitive interviews, many respondents had a more generalized interpretation of importance, considering how it related to daily living overall rather than the importance as a goal for improvement. Written instructions were modified in the GOAL-LD draft2 to improve clarity.

Suitability of the response scale

In the original version of the questionnaire (GOAL), the recall period (in the past 4 weeks) was problematic for the domain of Physical Activities, Sport \& Recreation, as some of these items were seasonal and many respondents checked the option "I did not do this in the past 4 weeks". One child commented "I've 
been living with this a long time, I know how these activities affect me even if I haven't done them in the past 4 weeks". Thus, in the GOAL-LD draft1, respondents were instructed to consider the past year for the activities in this domain. No further changes were suggested related to the response scale.

Ease of usage

Nine children (69\%) regarded the questionnaire as easy to complete. Three $(23 \%)$ felt the questionnaire was too long. Time required for children to complete the questionnaire versions varied from 12 to 19 minutes.

Overall, 23 of $30 \mathrm{HCP}$ respondents (77\%) stated they would consider using the questionnaire in their clinical practice and 27 (90\%) would apply for research purposes. Twenty-five HCPs who identified strengths of the GOAL-LD draft2 based on its content, with $13(52 \%)$ commenting that its comprehensiveness was an asset. However, 15 of $31 \mathrm{HCPs}(48 \%)$ responded that the amount of time required to administer the GOAL was "too long".

The Resulting GOAL-LD

The final iteration, the GOAL-LD, reflects the cumulative results of Phases 1 and 2 . It contains 45 items organized into six domains. Seven new items were added, 12 were eliminated, and 26 of the original 50 items were retained, as detailed in Additional file 3.

\section{Discussion}

End users should be involved in the development of PROMs to ensure they are relevant and meaningful. The intent of this study was to create an LD-specific HRQL outcome measure using a systematic iterative process of review and adaptation that involved all key stakeholders. Administration of the original GOAL to children with LD and their parents revealed that some items, particularly in domain A) ADLs \& Independence, did not pose a problem and consequently were not important goals for improvement, despite subsequent modifications to make some items more challenging. Consequently, this domain was eliminated to avoid a ceiling effect. Retention of such items would impede the questionnaire's ability to discriminate between children and restrict its sensitivity to change following interventions. This issue might explain the poor performance of other generic function measures such as the $\mathrm{CHQ}$ [6] and Activity Scale for Kids (ASK) $[16,36]$ when used in this population as many of their items pertain to ADLs. For example, the ASK has several questions related to personal care, dressing, standing skills, and transfers, which the results of this study indicate are not generally affected by LDs.

The decision to adapt the GOAL for children with LDs, as opposed to creating an entirely new measure, was made for several reasons. The content of the original GOAL was generated, in part, from review of existing outcome measures that included measures previously used for children with LDs (i.e., ASK [36] PODCI [13]). Further, working from the GOAL as a template required a shorter time frame than creating a new measure. The use of cognitive interviews in our study, and the opportunity for children, their parents, 
and HCPs to provide suggestions for modifications and new items, ensured the adaptations through the various iterations of the GOAL-LD were well informed. Cognitive interviewing is a critical component of outcome measure development that strongly complements field-testing of a questionnaire [28]. Children in this study were keen to talk about their personal experiences related to their LD and six new item suggestions were generated in this manner (e.g., wearing my choice of clothing, standing for a long time).

Domains that consistently performed well and required minimal content adaptation were $\mathrm{C}$ ) Pain/Discomfort/Fatigue and G) Body Image and Self-Esteem. Moreover, these items were rated as the most important goals across all versions of the GOAL. This makes sense, as for many children and their parents, eliminating the visible deformity and its psychosocial consequences is their primary motivation for reconstructive surgery $[7,37]$.

Of the seven new items added, two relate to adaptations not typically used for children with CP (i.e., use of a shoe-lift, and use of a prosthesis). Concern that some of the language might be too difficult was reflected in HCPs' comments but was not substantiated by children's responses in cognitive interviews or during questionnaire completion. While half the HCPs believed that the length of the GOAL might present a challenge, most children felt it was appropriate. This highlights the importance of involving the intended respondents in the development of PROMS. The questionnaire is intended to be selfadministered and completed at home or in the out-patient waiting room, meaning the time required to complete the questionnaire (range: 12-19 minutes) should not be difficult to accommodate, even in highvolume clinical settings.

\section{Limitations}

Although all key HCPs that work with children with LD were represented in our study (i.e., orthopedic surgeons, PTs, and nurse specialists), our sample was comprised primarily of orthopedic surgeons (81\%). It is not surprising that surgeons are over-represented in this sample, since they are the key HCP in the current model of care to inform treatment, and most often serve as primary investigators in related research initiatives. Their participation in the development of this outcome measure is key to its future uptake. The PT perspective is well represented in the development of this outcome measure as 3 of the study team members are PTs.

The performance of the final HCP-guided adaptation (GOAL-LD) was not evaluated with children and parents. However, it is reassuring that content revisions between the third and final iteration were minimal. For example, lineup became lineup/queue, and slopes become ramps/hills.

\section{Conclusion}

The GOAL-LD is a promising new outcome measure for comprehensively evaluating the physical and psychosocial wellbeing of children with LD. This paper focuses on the development of the GOAL-LD, its face and content validity, and highlights its sensibility. The GOAL-LD is presently undergoing 
psychometric evaluation of its reliability, construct validity and responsiveness in an international, multicenter study (UG Narayanan, L Donnan, oral communication, 2016) of children with LD and their parents. If validated, the GOAL-LD will facilitate individualized goal-setting and shared decision making about the choice and timing of intervention, while also serving as a meaningful HRQL outcome measure for pediatric LD in clinical and research contexts.

\section{Declarations}

\section{Acknowledgments}

Nancy Salbach was supported by funding from the Government of Ontario and the Canadian Institutes of Health Research to perform this research.

At the time this article was written Jennifer Dermott was a student at the Rehabilitation Sciences Institute, University of Toronto, Toronto, ON, Canada. This work forms part of her thesis dissertation. Graduate funding was provided through the University of Toronto Open Fellowship, SickKids Continuing Professional Development Fund, and Holland Bloorview Graduate Student Support.

\section{Author information}

Affiliations

\section{Division of Orthopaedic Surgery, Hospital for Sick Children, Toronto, ON, Canada}

Ms. Dermott, Dr. Narayanan

Department of Physical Therapy, Faculty of Medicine, University of Toronto, Toronto, ON, Canada

Drs. Wright and Salbach

Bloorview Research Institute, Holland Bloorview Kids Rehabilitation Hospital, Toronto, ON, Canada

Drs. Wright and Narayanan

Toronto Rehabilitation Institute, University Health Network, Toronto, ON, Canada

Dr. Salbach

Child Health Evaluative Sciences, Research Institute, Hospital for Sick Children, Toronto, ON, Canada

Dr. Narayanan

Department of Surgery and Rehabilitation Sciences Institute, Faculty of Medicine, University of Toronto, Toronto, ON, Canada

Dr. Narayanan 
Corresponding author

Correspondence to Jennifer A. Dermott

Author Contributions

- Substantial contributions to the conception or design of the work (all authors); or the acquisition (JD), analysis (JD, UN), or interpretation (JD, UN) of data for the work; and

- Drafting the work (JD) or revising it critically (all authors) for important intellectual content; and

- Final approval of the version to be published (all authors); and

- Agreement to be accountable for all aspects of the work in ensuring that questions related to the accuracy or integrity of any part of the work are appropriately investigated and resolved (all authors)

Ethics Declaration

Conflict of interest

All authors declare that they have no conflict of interest or competing interests.

Ethical approval

This study was approved by the research ethics board of Hospital for Sick Children, Holland Bloorview, and the University of Toronto.

Informed Consent

Children and their parents were informed verbally and in writing about the study and gave written informed consent.

\section{References}

1. Ephraim PL, Dillingham TR, Sector M, Pezzin LE, MacKenzie EJ. Epidemiology of limb loss and congenital limb deficiency: a review of the literature. Archives of Physical Medicine Rehabiliitation. 2003;84(5):747-61.

2. Guichet JM, Spivak JM, Trouilloud P, Grammont PM. Lower limb-length discrepancy. An epidemiologic study. Clin Orthop Relat Res. 1991;272:235-41.

3. Ghoneem HF, Wright JG, Cole WG, Rang M. The llizarov method for correction of complex deformities. The Journal of Bone Joint Surgery. 1996;78-A(10):6.

4. Kaufman K, Miller L, Sutherland D. Gait asymmetry in patients with limb-length inequality. J Pediatr Orthop. 1996;16(2):144-50.

5. Paley D. Principles of Deformity Correction. New York: Springer; 2005. 
6. Vitale M, Choe JC, Sesko AM, Hyman JE, Lee FY, Roye D, et al. The effect of leg length difference on health related quality of life: is the '2 cm rule' appropriate? J Pediatr Orthop. 2006;15(1):1-5.

7. Montpetit K, Hamdy RC, Dahan-Oliel N, Zhang X, Narayanan UG. Measurement of health-related quality of life in children undergoing external fixator treatment for lower limb deformities. $J$ Pediatr Orthop. 2009;29(8):920-6.

8. World Health Organization. The International Classification of Functioning, Disability and Health: ICF. Geneva: WHO; 2001.

9. Varni J, Burwinkle TM, Lane MM. Health-related quality of life measurement in pediatric clinical practice: An appraisal and precept for future research and application. Health Quality of Life Outcomes. 2005;3:34.

10. Hasler CC, Krieg AH. Current concepts of leg lengthening. J Child Orthop. 2012;6(2):89-104.

11. Narayanan UG. Outcomes Assessment of Fractures in Children. In: Mencio GA, Swiontkowski MF, editors. Green's Skeletal Trauma in Children. 5th ed. Philadelphia: Elsevier Saunders; 2015.

12. Landgraf JM, Maunsell E, Speechley KN, Bullinger M, Campbell S, Abetz L, et al. Canadian-French, German and UK versions of the Child Health Questionnaire: methodology and preliminary item scaling results. Qual Life Res. 1998;7:433-45.

13. Daltroy L, Liang MH, Fossel AH, Goldberg MJ. The POSNA Pediatric Musculoskeletal Functional Health Questionnaire: Report on reliability, validity, and sensitivity to change. J Pediatr Orthop. 1998;18(5):561-71.

14. Leet Al, Wientroub S, Kushner H, Brillante B, Kelly MH, Robey PG, et al. The correlation of specific orthopaedic features of polyostotic fibrous dysplasia with functional outcome scores in children. Journal of Bone Joint Surgery. 2006;88(4):818-23.

15. Lee KM, Chung CY, Gwon DK, Sung KH, Cho JH, Kim TW, et al. Parental perspectives on leg length discrepancy. Journal of Pediatric Orthopedics B. 2012;21(2):146-9.

16. Sheiko M, Bjornson K, Lisle J, Song KM, Eary JF, Conrad EU. Physical activity assessment in adolescents with limb salvage. J Pediatr Orthop. 2012;161(6):1138-41.

17. Narayanan UG. Concerns, desires and expectations of surgery for adolescent idiopathic scoliosis: A comparison of patients', parents' and surgeons' perspectives. Toronto: Univesity of Toronto; 2008.

18. Narayanan UG. Framework of patient priorities. Available from:

https://lab.research.sickkids.ca/pscoreprogram/framework-of-patient-priorities/.

19. Narayanan UG, Moline R, Encisa C, Yeung C, Weir S. Validation of the GOAL questionnaire: an outcome measure for ambulatory children with cerebral palsy. Developmental Medicine Child Neurology. 2015;57(S5):29.

20. Thomason P, Tan A, Donnan A, Rodda J, Graham HK, \& U.G., N. The Gait Outcomes Assessment List (GOAL): validation of a new assessment of gait function for children with cerebral palsy. Developmental Medicine Child Neurology. 2018;60(6):618-23. 
21. Law M, Baptiste S, McColl MA, Opzoomer A, Polatajko H, Pollock N. The Canadian Occupational Performance Measure: an outcome measure for occupational therapy. Canadian Journal of Occupational Therapy - Revue Canadienne d Ergotherapie. 1990;57(2):82-7.

22. Kiresuk TJ, Sherman RE. Goal Attainment Scaling: A general method for evaluating comprehensive community mental health programs. Community Ment Health J. 1968;4(6):443-53.

23. Harpster K, Sheehan A, Foster EA, Leffler E, Schwab SM, Angeli JM. The methodological application of goal attainment scaling in pediatric rehabilitation research: a systematic review. Disabil Rehabil. 2019;41(24):2855-64.

24. Tam C, Teachman G, Wright V. Paediatric application of individualised client-centred outcome measures: a literature review. British Journal of Occupational Therapy. 2008;71(7):286-96.

25. Stewart S, Neyerlin-Beale J. (1999). Enhancing independence in children with cerebral palsy. Symposium on cerebral palsy. British Journal of Therapy and Rehabilitation, 6, 574-579.

26. Narayanan UG, Davidson B, Weir S. Gait Outcomes Assessment List (The GOAL): Developing a meaningful outcome measure for ambulatory children with cerebral palsy. Developmental Medicine Child Neurology. 2011;53:79.

27. Rowe $B H, O x m a n A D$. An assessment of the sensibility of a quality-of-life instrument. The American Journal of Emergency Medicine. 1993;11(4):374-80.

28. Wooley ME, Bowen GL, Bowen NK. Cognitive pretesting and the developmental validity of child selfreport instruments: theory and application. Research on Social Work Practice. 2004;14(3):191-200.

29. Feinstein AR. Clinimetrics. New Haven: Yale University Press; 1987.

30. O'Brien KK, Bayoumi AM, Bereket T, Swinton M, Alexander R, King K, et al. Sensibility assessment of the HIV Disability Questionnaire. Disabil Rehabil. 2013;35(7):566-77.

31. FluidSurveys. http:://http://www.fluidsurveys.com2012.

32. Wilson A, Kavanaugh A, Moher R, Mclnroy M, Gupta N, Salbach NM, et al. Development and pilot testing of the Challenge Module: a proposed adjunt to the Gross Motor Function Measure for high functioning children with cerebral palsy. Physical Occupational Therapy in Pediatrics. 2011;31(2):135-49.

33. R Core Team. R: A language and environment for statistical computing (2014). http://www.Rproject.org.

34. Willis GB. Analysis of the cognitive interview in questionnaire design. New York: Oxford University Press; 2015.

35. Tetsworth K, Paley D. Malalignment and degenerative arthropathy. Orthop Clin North Am. 1994;25(3):367-77.

36. Young NL, Williams JI, Yoshida KK, Wright JG. Measurement properties of the Activities Scale for Kids. J Clin Epidemiol. 2000;53(2):125-37.

37. Bond JM, Kent GG, Binney VA, Saleh M. Psychological adjustment of children awaiting limb reconstruction. Child: Care Health Development. 1999;25(4):313-32. 
Figures

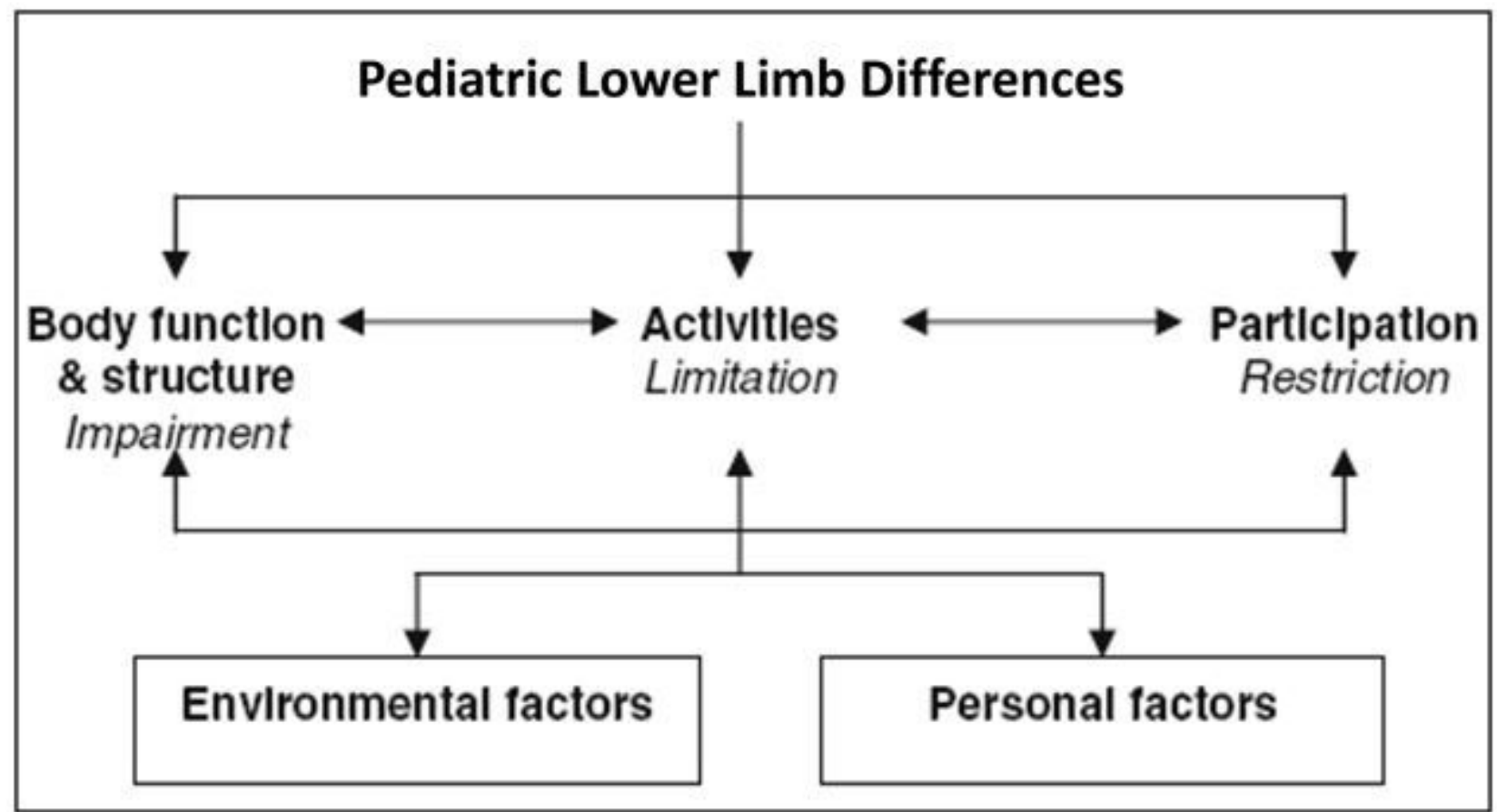

Figure 1

The International Classification of Functioning, Disability and Health (ICF) conceptualizes the consequences and outcomes of LD [8] 


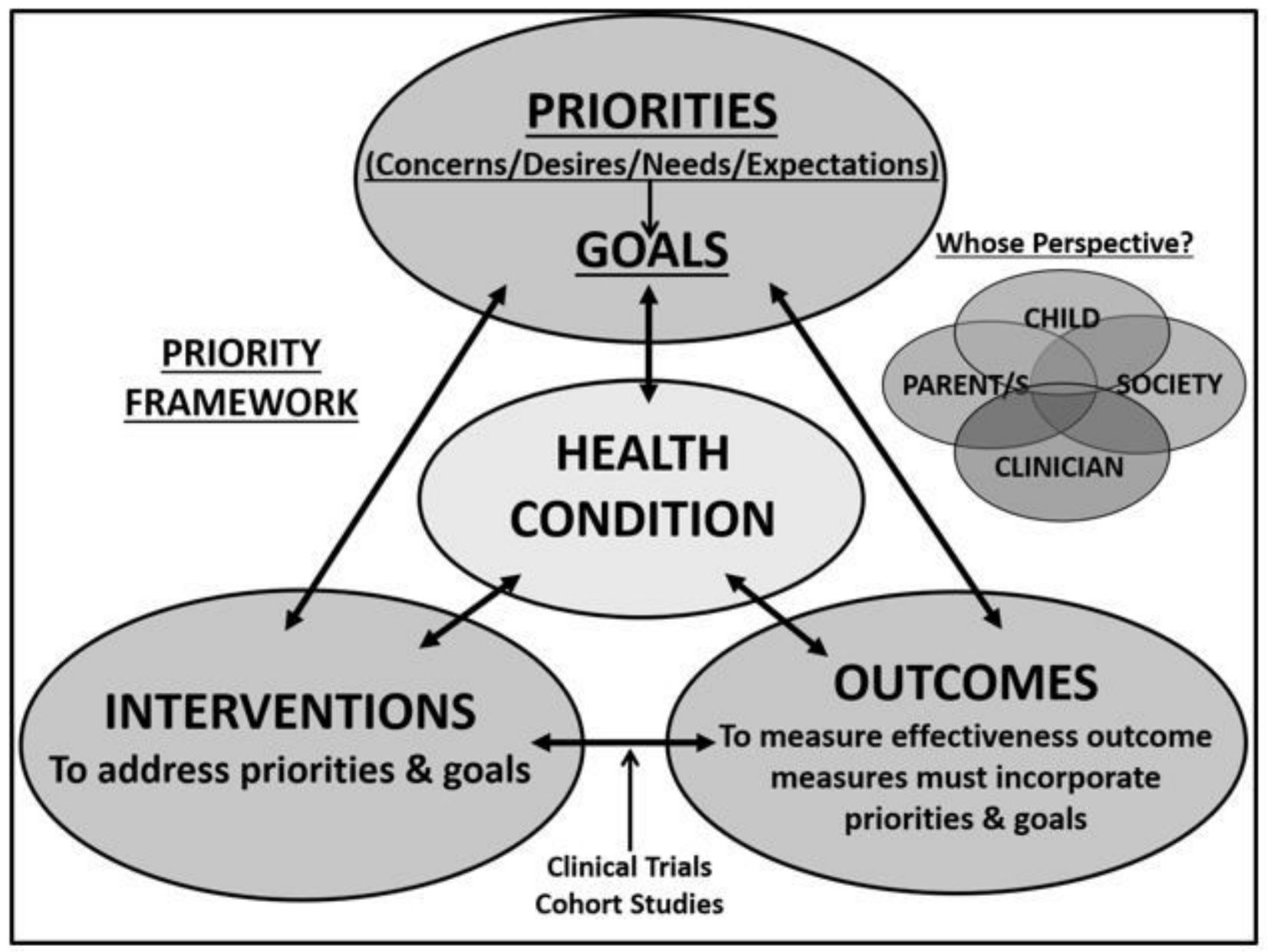

Figure 2

Priority Framework for Outcomes Assessment $[17,18]$ : Adapted from https://lab.research.sickkids.ca/pscoreprogram/framework-of-patient-priorities/ 
Fig. 3

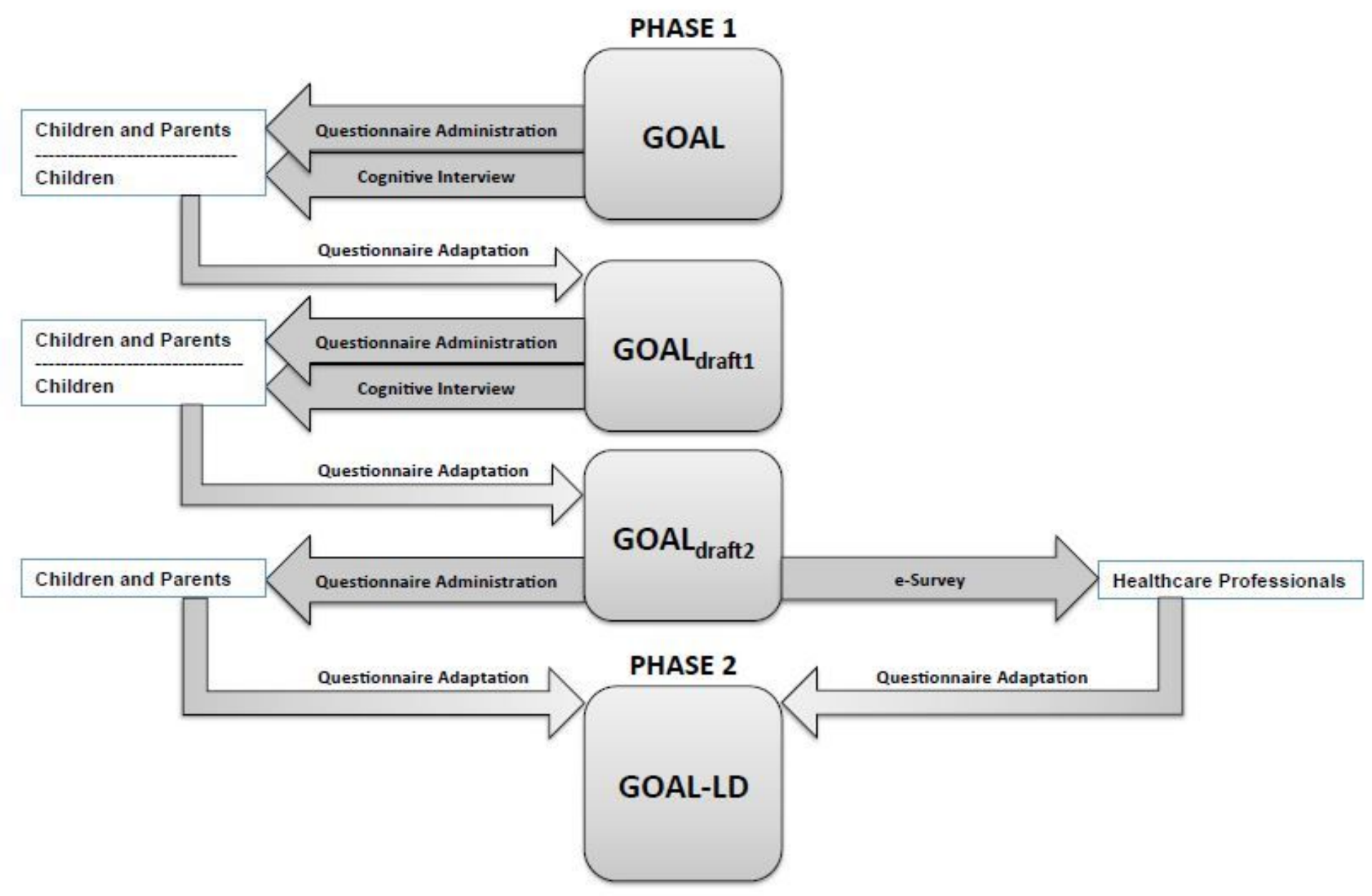

\section{Figure 3}

Flow diagram of study events

\section{Supplementary Files}

This is a list of supplementary files associated with this preprint. Click to download.

- Additionalfile3.pdf

- Additionalfile21.docx

- Additionalfile1.docx 